05

\title{
Эластокалорический эффект в резине при периодическом воздействии растягивающей силы
}

\author{
() Е.В. Морозов, Д.С. Кучин, В.В. Коледов, В.Г. Шавров
}

Институт радиотехники и электроники им. В.А. Котельникова РАН, 125009 Москва, Россия

e-mail: evgvmorozov@gmail.com

(Поступило в Редакцию 19 апреля 2016 г.)

\begin{abstract}
Экспериментально изучен эластокалорический эффект (ЭКЭ) в латексной резине при периодическом воздействии растягивающей силы. ЭКЭ измерен в зависимости от относительного удлинения и частоты циклов до $4 \mathrm{~Hz}$. Выявлено три диапазона частот циклов, при которых проявляются различные термодинамические процессы: эластокалорическое охлаждение, саморазогрев и уменьшение ЭКЭ. Максимальная измеренная величина ЭКЭ в латексной резине достигает $14 \mathrm{~K}$ при относительной деформации образца, равной $700 \%$, и частотах от 0.1 до $0.3 \mathrm{~Hz}$. Также обсуждена возможность практического использования латексной резины для эластокалорического охлаждения.
\end{abstract}

\section{Введение}

В последние годы во всем мире создаются новые функциональные материалы, например, сплавы с фазовыми переходами, в которых внешние поля вызывают резкое изменение энтропии и температуры. Это направление признано перспективным для создания альтернативных твердотельных энергетических систем, таких как холодильники и тепловые насосы. Для решения этих задач изучаются магнитокалорический, электрокалорический и эластокалорический эффекты. Они связаны с изменением температуры изучаемого образца под воздействием на него различных внешних полей: магнитного, электрического или поля механических напряжений $[1,2]$. Настоящая работа посвящена эластокалорическому эффекту (ЭКЭ) в латексной резине. Латексная резина не является твердым телом в классическом понимании, ее внутренняя структура представляет собой сеть взаимосвязанных полимерных цепей. По классификации состояний вещества резина является высокоэластичным полимером (эластомером). Структура полимеров представляет собой звенья, соединенные в единую цепь, которые не могут перемещаться в пространстве независимо. Это является причиной аномально низкой энтропии резины [3]. Также латексная резина обладает отрицательным коэффициентом теплового расширения [4].

При растяжении образца из латексной резины (эластомера) цепи образца растягиваются, таким образом принимая наименее вероятную конфигурацию. Это означает уменьшение энтропии эластомера и свидетельствует об энтропийной природе упругости. Из вышесказанного можно заключить, что причиной нагрева образца при растяжении и охлаждения его при обратном сжатии является энтропийная упругость [5].

В последнее время ЭКЭ в резиноподобных материалах вызывает растущий интерес $[2,6]$. Показано, что ЭКЭ в резине имеет величину, составляющую более $10 \mathrm{~K}$. Однако неизученными до сих пор являются вопросы, связанные с зависимостью ЭКЭ от частоты циклов и, следовательно, отсутствуют оценки максимальной удельной мощности охлаждения за счет ЭКЭ.

Целью настоящего исследования было изучение ЭКЭ в латексной резине при периодическом воздействии растягивающей силы в зависимости от относительной деформации и частоты циклов растяжения-сжатия, а также оценки достижимой удельной мощности рабочего тела холодильника на основе ЭКЭ в латексной резине.

\section{1. Экспериментальная часть}

\section{1. Экспериментальная установка}

Для изучения ЭКЭ в латексной резине создана экспериментальная установка, схема которой показана на рис. 1. Установка состоит из двух жестко закрепленных, расположенных навстречу друг другу, актюаторов 2 с длиной хода $22 \mathrm{~mm}$, подключенных к импульсному

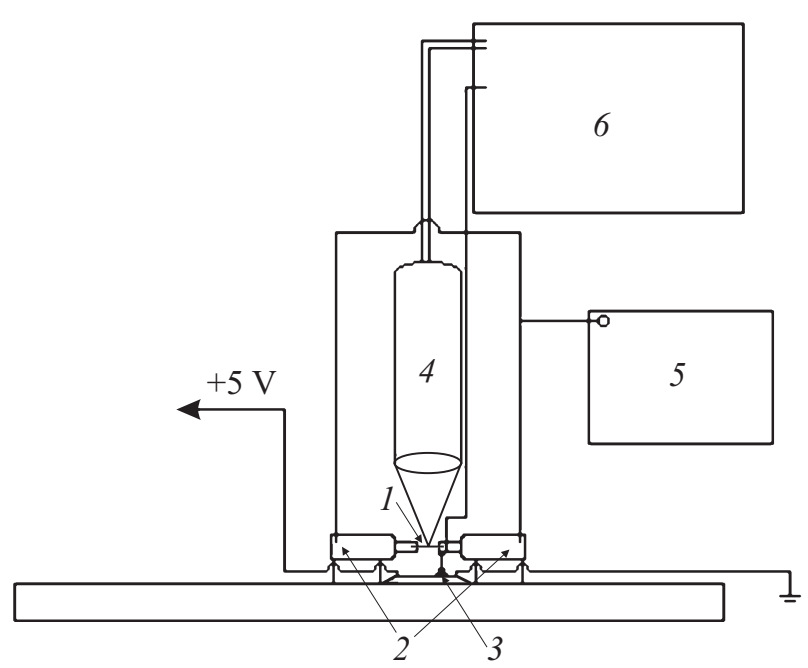

Рис. 1. Схема экспериментальной установки для изучения ЭКЭ. 

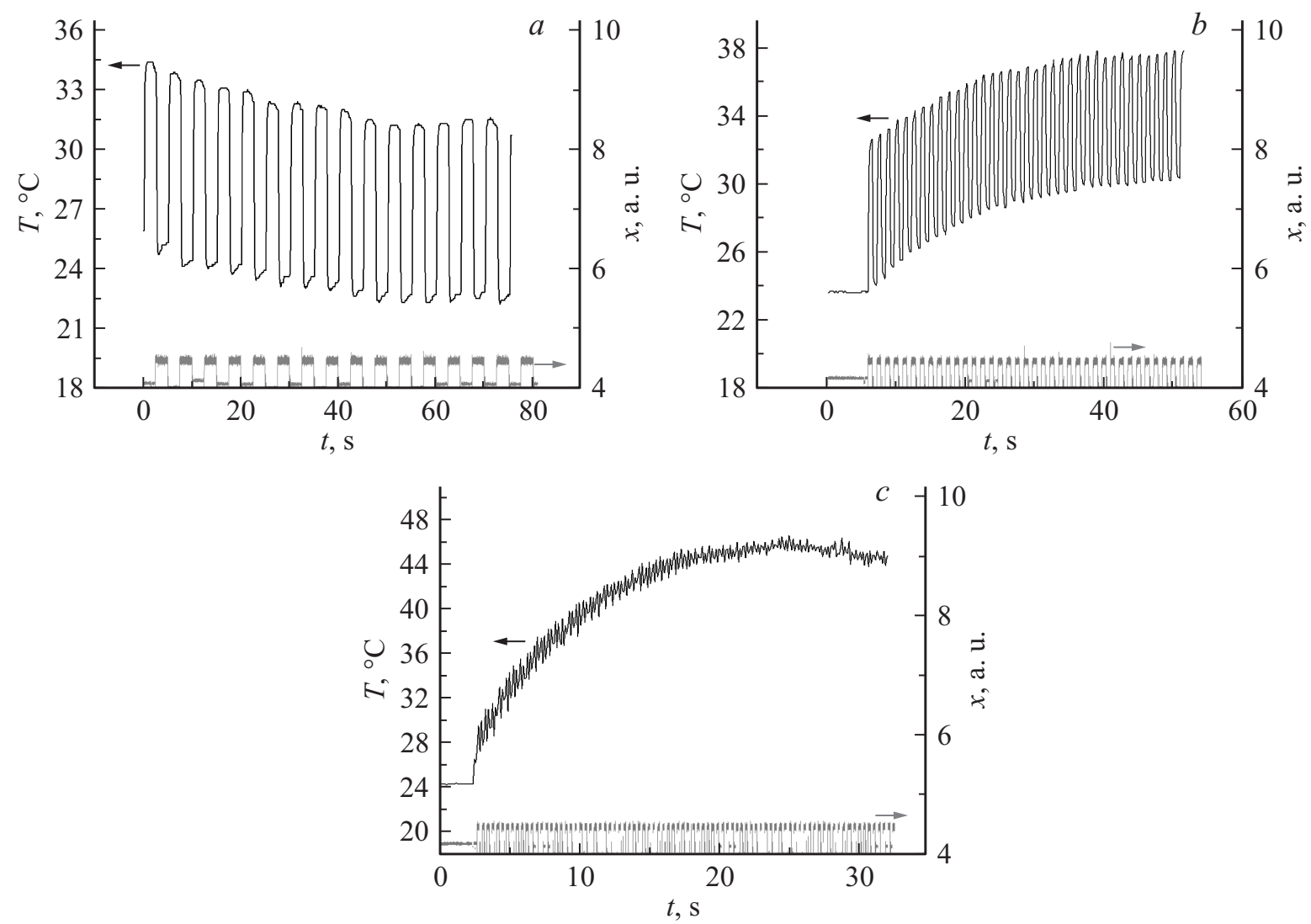

Рис. 2. Временные зависимости температуры и деформации в образце резины при периодическом растяжении с частотой: $a-$ $0.2 \mathrm{~Hz}, b-0.8 \mathrm{~Hz}, c-4 \mathrm{~Hz}$.

генератору напряжения 5. Актюаторы обеспечивают периодическую деформацию растяжения исследуемого образца 1, закрепленного между ними. Для измерения деформации образца используется резистивный датчик перемещения 3. Температура поверхности образца измеряется дистанционно с помощью пирометрического датчика 4 марки testo 845 с частотой циклов измерения $10 \mathrm{~Hz}$. Пирометр сфокусирован в центре образца для измерения температуры в определенной неподвижной точке. Для сбора и обработки данных используется персональный компьютер 6 с платой АЦП L-CARD E14-140M.

\section{2. Проведенные эксперименты}

В качестве исследуемого материала была выбрана латексная резина. В отличие от металлических функциональных материалов, величина обратимой деформации которых имеет порядок долей или единиц процентов, обратимая деформация резины составляет сотни процентов. Это позволяет более точно изучить ЭКЭ.

Образцы представляют собой ленты из латексной резины шириной $5 \mathrm{~mm}$, толщиной $0.6 \mathrm{~mm}$ и длиной от 7.3 до $44 \mathrm{~mm}$. Был измерен ЭКЭ при периодическом воздействии внешней нагрузки частотой циклов от 0.1 до $4 \mathrm{~Hz}$, относительная деформация изменялась от 200 до 500\%. Также измерения проводились при относительной деформации $700 \%$.

\section{2. Результаты экспериментов}

Как было сказано выше, причиной нагрева резинового образца при растяжении и охлаждения при сжатии является энтропийная упругость. При воздействии внешней силы полимерные цепи растягиваются, принимая, таким образом, менее вероятное энергетическое состояние с меньшей энтропией [4]. В почти адиабатических условиях быстрых циклов растяжения/сжатия это должно приводить к быстрому обратимому изменению температуры образца. При снижении частоты циклов свою роль должен сыграть теплообмен образца с окружающим воздухом, а при слишком высоких частотах - процессы внутреннего производства энтропии - трения.

На рис. 2 изображена зависимость температуры образца от его деформации (ЭКЭ) при воздействии на него периодической нагрузки величиной $4 \mathrm{MPa}$.

На приведенных графика виден как сам ЭКЭ обратимое изменение температуры, синхронное изменению деформации образца, так и резкое уменьшение ЭКЭ с увеличением частоты циклов растяжения-сжатия образца. График зависимости эффекта от частоты приведен на рис. 3. Обращает внимание поведение средней 


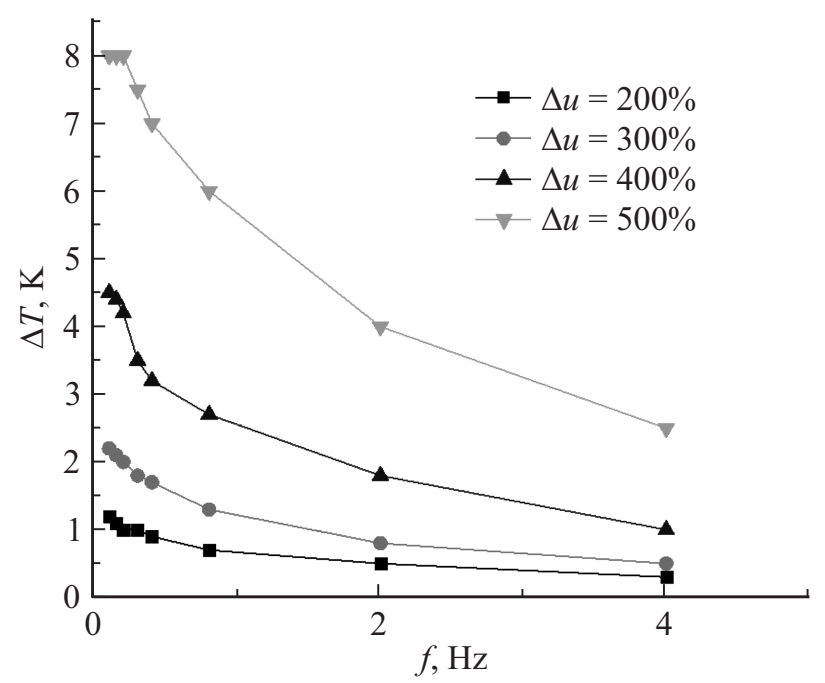

Рис. 3. Зависимость величины эластокалорического эффекта от частоты воздействия периодической силы. температуры образца за период. При малых частотах имеет место охлаждение образца в среднем, которое сменяется нагревом при увеличении частоты.

Исследовался также ЭКЭ при обдувании образца воздухом с помощью вентилятора, что вызывало отток тепла и, таким образом, компенсировало саморазогрев, проявляющийся при высоких частотах. Рис. 4 показывает влияние принудительной конвекции на ЭКЭ при разных частотах периодической растягивающей силы. Вентилятор включался в тот момент, когда средняя температура образца принимала постоянное значение.

Из приведенных графиков видно, что в изучаемом частотном диапазоне $(0.1-4 \mathrm{~Hz})$ можно выделить качественно три характерных интервала. Назовем их: низкие $(0.1-0.3 \mathrm{~Hz})$, средние $(0.4-0.8 \mathrm{~Hz})$ и высокие $(1-4 \mathrm{~Hz})$.

При низких частотах в образце происходит процесс охлаждения образца в среднем, что видно на рис. 5. Это можно объяснить следующим образом. При быстром
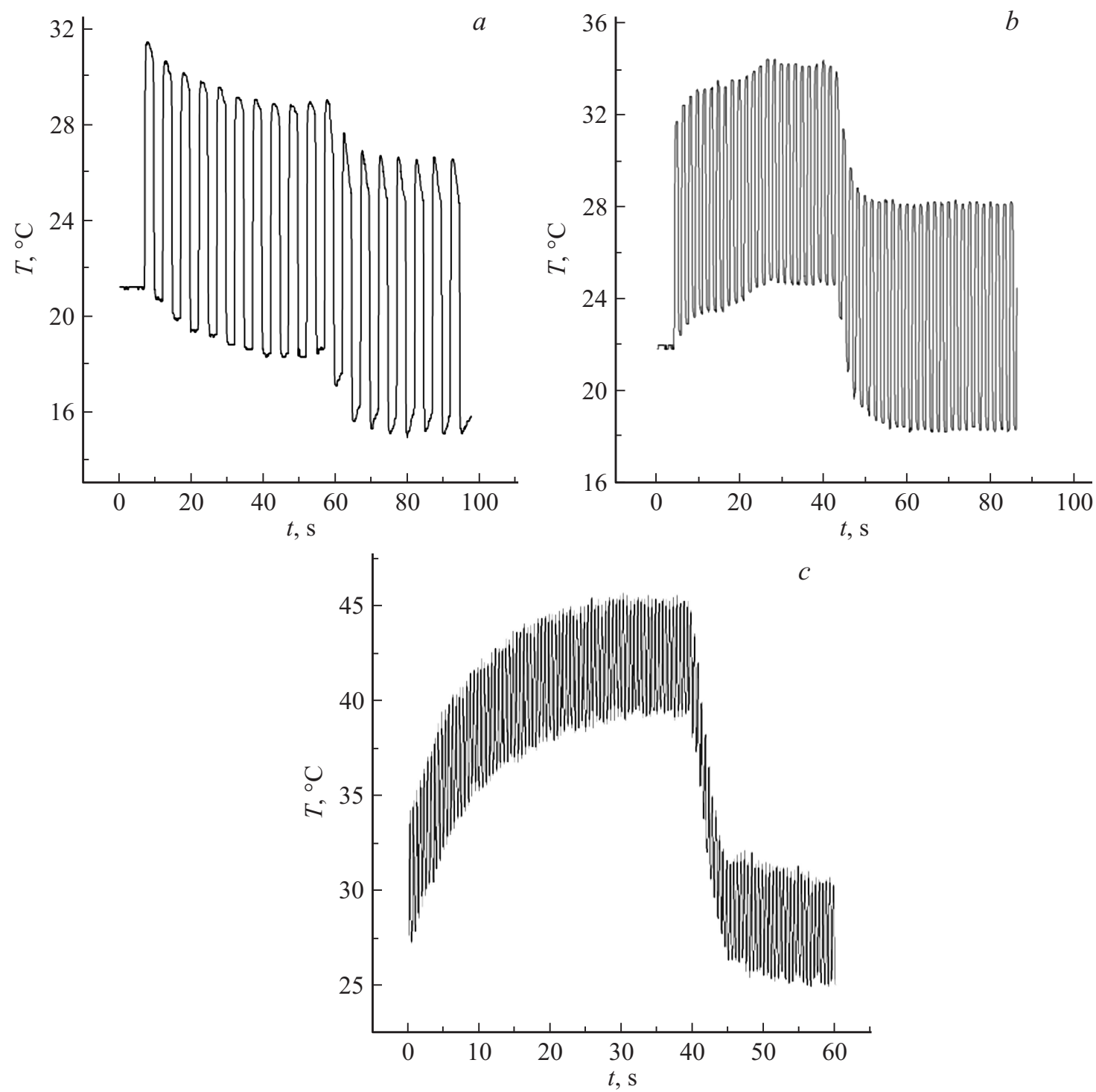

Рис. 4. Влияние принудительной конвекции на ЭКЭ при частоте периодической растягивающей силы: $a-0.2 \mathrm{~Hz}, b-0.8 \mathrm{~Hz}$, $c-2 \mathrm{~Hz}$. 


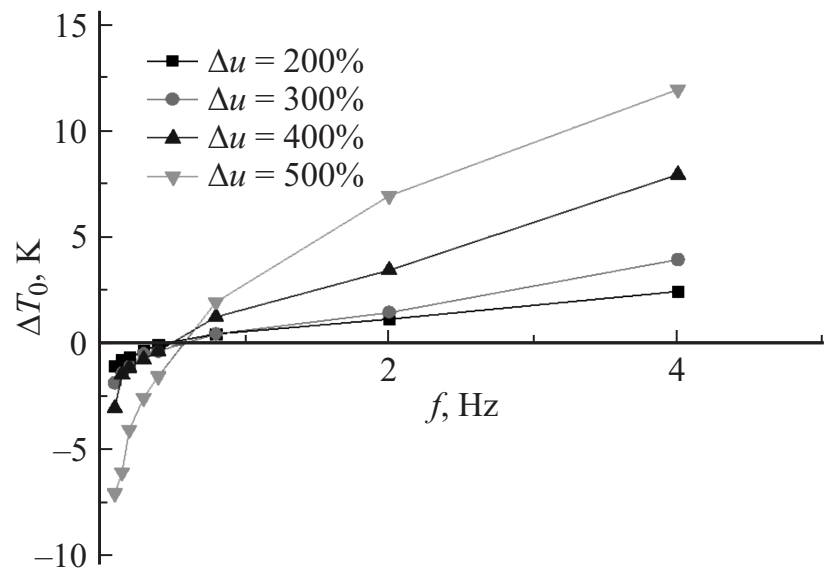

Рис. 5. Зависимость изменения наименьшей температуры образца относительно его начальной (комнатной) температуры при периодическом воздействии растягивающей силы.

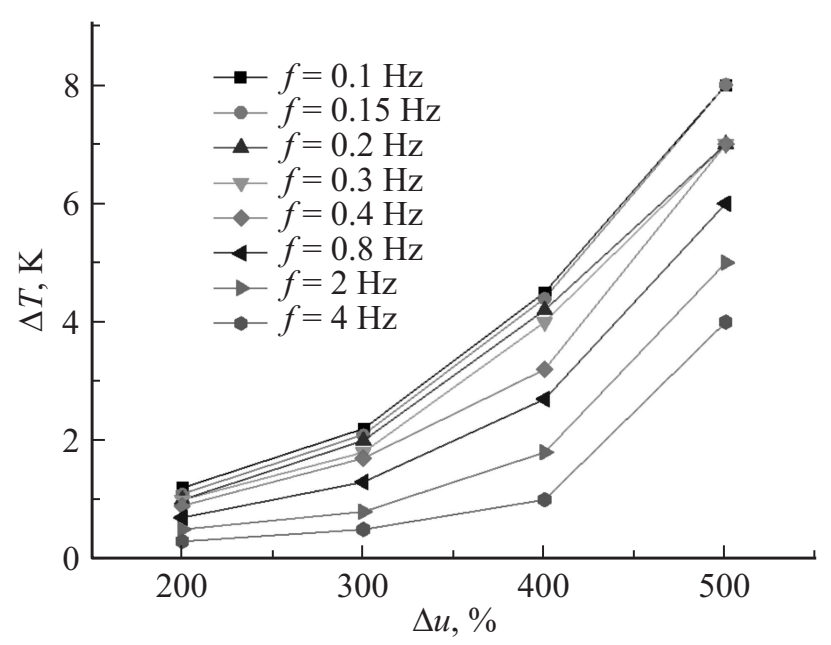

Рис. 6. Зависимость ЭКЭ в образце латексной резины от его деформации.

(адиабатическом) растяжении эластомер нагревается. Далее, находясь в растянутом состоянии, он охлаждается, в результате теплообмен с окружающей средой. После чего происходит быстрое (адиабатическое) сжатие, в результате которого температура образца падает и, таким образом, она становится ниже начальной комнатной. Разогрев в сжатом состоянии при теплообмене с окружающей средой происходит медленнее, чем охлаждение в растянутом, поскольку разница между температурой образца эластомера и комнатной температурой меньше чем в растянутом состоянии. Поэтому через некоторое количество циклов устанавливается минимальная температура в образце ниже комнатной температуры.

В среднечастотном диапазоне в эластомере виден эффект саморазогрева. Причиной этого эффекта, по-видимому, является внутреннее трение, которое и повышает среднюю температуру образца, но в отличие от низких частот времени теплообмена с окружающей средой недостаточно для того, чтобы средняя температура образца уменьшалась или оставалась постоянной.

Как видно на рис. 3, для частот низкого и среднего диапазона величина ЭКЭ почти не меняется. При высоких частотах растяжения-сжатия величина ЭКЭ сильно падает (рис. 3). Для выяснения природы этого эффекта были произведены исследования с принудительным отводом тепла (рис. 4). Из предложенных графиков видно, что при частоте $2 \mathrm{~Hz}$ (интервал высоких частот) величина ЭКЭ уменьшается, хотя средняя температура образца повышается. Принудительная конвекция приводит к снижению средней температуры, но не приводит к увеличению ЭКЭ. Из этого можно сделать вывод, что саморазогрев не является причиной уменьшения ЭКЭ при увеличении частоты циклов.

Используя модель ЭКЭ, представленную в работе [2], можно качественно объяснить уменьшение ЭКЭ при частотах более $1 \mathrm{~Hz}$. Латексная резина состоит из полимерных цепей, сшитых между собой перекрестными связями. При растяжении эластомера полимерные цепи вытягиваются, а перекрестные связи изменяются и при обратном сжатии приходят в исходное состояние. При больших частотах сеть полимерных цепей и перекрестных связей изменяется при растяжении, но времени на их восстановление при сжатии оказывается недостаточно, что и является причиной уменьшения ЭКЭ при частотах растяжения-сжатия образца больше $1 \mathrm{~Hz}$.

Зависимость ЭКЭ от деформации при разных частотах представлена на рис. 6. Известно, что в твердом теле при малых деформациях зависимость изменения температуры от деформации имеет линейный характер [7]. При изучении такой зависимости в латексной резине, которая не является твердым телом в классическом понимании и выдерживает гигантские обратимые относительной деформации (до 500-700\%) наблюдается нелинейная зависимость ЭКЭ от деформации.

\section{3. Обсуждение результатов}

С целью обсуждения возможности практического использования латексной резины для эластокалорического охлаждения построена зависимость удельной мощности эластомера от частоты циклов растяжения-сжатия при относительной деформации, равной 500\% (рис. 7).

Удельная мощность рассчитывалась по формуле

$$
W=c \cdot \Delta T \cdot f,
$$

где $c \approx 1.0 \mathrm{~J} /(\mathrm{g} \cdot \mathrm{K})$ - удельная теплоемкость образца резины, $\Delta T$ - изменение температуры образца за счет ЭКЭ, $f$ - частота циклов периодического воздействия растягивающей силы.

Как видно из представленной на рис. 7 зависимости, удельная мощность увеличивается с увеличением частоты циклов и при частоте, равной $4 \mathrm{~Hz}$, и достигает величины порядка $10 \mathrm{~W} / \mathrm{g}$. Это - значительная величина, вполне сравнимая или превосходящая значения 


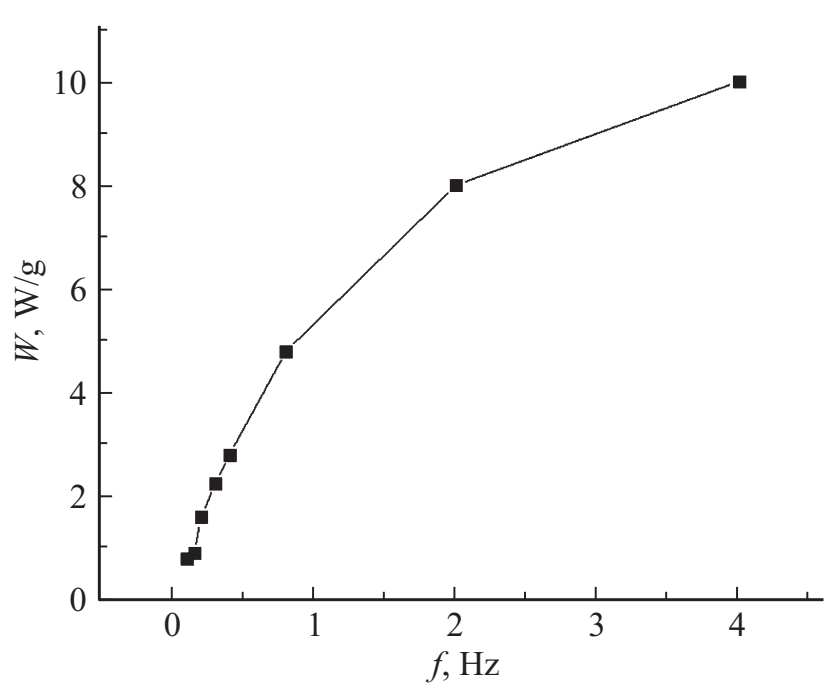

Рис. 7. Зависимость удельной мощности эластомера от частоты циклов растяжения-сжатия при относительном удлинении $500 \%$.

удельной мощности для магнитокалорических материалов, которым в последние годы посвящено много работ [8-13]. Основная проблема заключается в том, что при бо́льших частотах имеет место очень сильный саморазогрев образца, а затем разрушение. В результате чего долговечность его работы при $f>1 \mathrm{~Hz}$ составляет порядка 1000 циклов, что обеспечивает лишь 5-10 min непрерывной работы. Для создания твердотельного холодильника широкого применения необходим материал, способный выдерживать без деградации такое количество циклов, чтобы время работы составляло $10^{7}-10^{8} \mathrm{~s}$. Очевидно, что большую роль для обеспечения долговечности играет среда-теплоноситель, окружающая активный материал с ЭКЭ. В магнитокалорических холодильниках, использующих активный материал на основе гадолиния или металлических ферромагнитных сплавов, в качестве теплоносителя применяется вода или водно-спиртовой раствор. Ясно, что попыткам реализации практического прототипа холодильника на основе ЭКЭ в резине должны предшествовать материаловедческие исследования по поиску пары образец-теплоноситель, способной обеспечить длительную устойчивую работу под быстро изменяющейся интенсивной механической и тепловой нагрузкой.

\section{Заключение}

В заключение сформулируем результаты настоящей работы.

1. В латексной резине при комнатной температуре наблюдается ЭКЭ, максимальная измеренная величина которого достигает $14 \mathrm{~K}$.

2. В результате исследования ЭКЭ при периодическом воздействии в диапазоне частот $0.1-4 \mathrm{~Hz}$ растягивающей силы были выявлены три диапазона частот цик- лов, при которых проявляются качественно различные режимы: эластокалорическое охлаждение, саморазогрев и уменьшение ЭКЭ.

3. Показано, что в латексной резине при деформациях величиной в сотни процентов зависимость температуры образца от его удлинения является нелинейной.

4. Произведена оценка удельной мощности образца латексной резины в зависимости от частоты растягивающей силы. В изучаемом диапазоне частот удельная мощность достигает максимального значения при частоте $f=4 \mathrm{~Hz}$ и равна $W=10 \mathrm{~W} / \mathrm{g}$.

Работа выполнена при поддержке гранта РФФИ № 15-07-08806.

\section{Список литературы}

[1] Haussühl S. Physical Properties of Crystals: an Introduction, John Wiley \& Sons, 2008.

[2] Guyomar D. et al. // Applied Thermal Engineering. 2013. Vol. 57. P. 33-38.

[3] http://polly.phys.msu.ru/en/education/courses/polymer-intro/ lecture1rus.pdf

[4] Кулезнев В.Н. Химия и физика полимеров, 1988. С. 109110.

[5] http://polly.phys.msu.ru/en/education/courses/polymer-intro/ lecture3rus.pdf

[6] Holzapfel G.A., Sirno J.C. // Comput. Methods Appl. Mech. Engrg. 1996. Vol. 132. P. 17-44.

[7] Ландау Л.Д., Либшии, Е.М. Теоретическая физика. Т. 7. Теория упругости. 1987. С. 29.

[8] Kamantsev A.P., Koledov V.V., Mashirov A.V., Dilmieva E.T., Shavrov V.G., Cwik J., Tereshina I.S. // Bulletin of the Russian Academy of Sciences. Physics. 2014. Vol. 78. N 9. P. 936-938.

[9] Fayzullin R., Buchelnikov V., Drobosyuk M., Mashirov A., Kamantsev A., Hernando B., Zhukov M., Koledov V., Shavrov V. // Solid State Phenomena. 2015. Vol. 233-234. P. 183-186.

[10] Kamantsev A.P., Koledov V.V., Mashirov A.V., Dilmieva E.T., Shavrov V.G., Cwik J., Tereshina I.S. // Solid State Phenomena. 2015. Vol. 233-234. P. 216-219.

[11] Kamantsev A.P., Koledov V.V., Mashirov A.V., Dilmieva E.T., Shavrov V.G., Cwik J., Los A.S., Nizhankovskii V.I., Rogacki K., TereshinaI.S., Koshkid'ko Yu.S., Lyange M.V., Khovaylo V.V., Ari-Gur P. // J. Appl. Phys. 2015. Vol. 117. N 16. P. 163903.

[12] Kamantsev I.P., Koledov V.V., Mashirov A.V., Dilmieva E.T., Shavrov V.G., Cwik J., Tereshina I.S., Lyange M.V., Khovaylo V.V., Porcari J., Topic M. // Bulletin of the Russian Academy of Sciences. Physics. 2015. Vol. 79. N 9. P. 10861088.

[13] Guillou F., Yibole H., Kamantsev A., Porcari G., Cwik J., Koledov V., van Dijk N.H., Brück E. // IEEE Transactions on Magnetics. 2015. Vol. 51. N 11. P. 2503904. 